\title{
O PROJETO POLÍTICO QUILOMBOLA: DESAFIOS, CONQUISTAS E IMPASSES ATUAIS
}

\author{
ILKA BOAVENTURA LEITE \\ Universidade Federal de Santa Catarina
}

\begin{abstract}
Resumo: O projeto político Quilombola atravessou séculos de história para se consolidar como direito constitucional. O quilombo ampliou-se por meio do apoio de outras parcelas da população brasileira, tornando-se parte de um projeto político nacional voltado para a construção de uma sociedade mais democrática e justa. As contradições entre a Legislação e a sua efetiva aplicação, contudo, constituem hoje o maior desafio, uma vez que a incorporação do quilombo na ordem jurídica não tem sido suficiente para alterar as práticas de expropriação e controle da terra, e com elas a situação de precariedade em que vivem os grupos negros na atualidade. A ação estatal de proteção às chamadas comunidades quilombolas tem se ampliado e pode até ser considerada uma prática inovadora hoje, mas se demonstra ainda muito insuficiente, requerendo uma ação redobrada de participação política por parte dos movimentos sociais negros no Brasil.
\end{abstract}

Palavras-chave: quilombos; direitos étnicos; diáspora; identidade; ações afirmativas.

\section{Quilombo e resistência}

A palavra "quilombo", que em sua etimologia bantu quer dizer acampamento guerreiro na floresta, foi popularizada no Brasil pela administração colonial, em suas leis, relatórios, atos e decretos, para se referir às unidades de apoio mútuo criadas pelos rebeldes ao sistema escravista e às suas reações, organizações e lutas pelo fim da escravidão no País. Essa palavra teve também um significado especial para os libertos, em sua trajetória, conquista e liberdade, alcançando amplas dimensões e conteúdos. $O$ fato mais emblemático é o do Quilombo dos Palmares, movimento rebelde que se opôs à administração colonial por quase dois séculos.

As centenas de insurreições de escravos e as formas mais diversas de rejeição ao sistema escravista no período colonial fizeram da palavra "quilombo" um marco da luta contra a dominação colonial e de todas as lutas dos negros que se seguiram após a

Copyright $\odot 2008$ by Revista Estudos Feministas. 
quebra desses laços institucionais. A Legis/ação Ultramarina em sua fase áurea definiu como sendo um quilombo a reunião de mais de cinco negros - tal era o potencial de revolta contido na união dos escravos. Quilombo e liberdade são, portanto, contrafaces de uma mesma realidade histórica. De um lado, as situações de força arbitrária e incontestável em que os "senhores" impunham a sua vontade por meio de atitudes explícitas ou dissimuladas, brandas ou violentas. De outro, as reações dos escravos e libertos, explícitas, sutis, violentas ou não, às diversas situações e regimes de autoridade.

No final do século XIX, com a quebra dos vínculos coloniais e as mudanças decorrentes dos projetos de industrialização no Brasil, o quilombo ampliou-se para outras parcelas da população, indo da voz dos abolicionistas para os movimentos sociais, tornando-se uma parte do projeto político de uma sociedade mais democrática e justa. Principalmente as áreas rurais de diversas regiões do Brasil, a gênese da formação escravista que teve o quilombo como sua maior referência, deslocam-se pelo período de transição da economia colonial sem uma ruptura ou quebra dos antigos vínculos senhoriais. A unidade familiar que serviu de suporte ao modo de produção colonial incorpora o processo produtivo de acamponesamento das populações recém-saídas da escravidão. Concomitantemente ao processo de desagregação das grandes fazendas voltadas para a exportação e à diminuição do poder de coerção dos grandes proprietários territoriais, os quilombos passaram a integrar a ordem pós-abolicionista' relacionando-se, não sem conflitos, com as estruturas pós-coloniais.

A abolição do trabalho escravo, porém, não alterou substancialmente as práticas de expropriação e controle da terra, e com elas a situação dos grupos negros. Nesse processo de dominação continuada, os descendentes dos africanos escravizados passam a operar por meio da dinâmica da territorialização étnica, ${ }^{2}$ modelo que, em algumas regiões mais do que em outras, consistia em posicionar as populações nativas, os africanos e seus descendentes, em e na relação com os imigrantes recém-chegados, reconfigurandose ainda lógicas racialistas anteriormente implantadas.

Enquanto para os índios a solução contra o extermínio foi o aldeamento e a tutela estatal, para os negros restou a longa etapa de marginalização social e política da qual decorreu uma lógica de segregação sutil, disfarçada pela ideologia da mestiçagem. Essa lógica introduziu um modelo de relações interétnicas que se adaptou à ideologia racial em vigor. Veja-se o exemplo da região Sul do Brasil.

A diversidade étnico-cultural atribuída à região Sul do Brasil, da qual fazem parte os Estados do Rio Grande do Sul, Paraná e Santa Catarina, decorre, em parte, da forma de ocupação do espaço geográfico iniciado no período colonial, mas principalmente na última década do século XIX, com a imigração européia. Se comparada estatisticamente ao resto do Brasil, a região Sul parece constituir-se como uma das áreas de menor porcentagem de índios e negros. A maior parte de suas terras foi reocupada, na transição do século XIX para o XX, por imigrantes procedentes de diversas regiões da Europa. A presença maciça de imigrantes delineou um novo perfil sociocultural nessa parte do País. O padrão de colonização com imigrantes europeus reforçou as fronteiras internas pela correlação entre espaço territorial e origem dos contingentes populacionais transplantados. Esses grupos recém-chegados reposicionaram-se como grupos étnicos e, por meio da elaboração de novos signos e emblemas, introduziram uma releitura de suas tradições desde a nova conjuntura, como colonos, da nação de procedência e da nação de adoção. Ao chegarem como pomeranos, vênetos, trentinos, ungareses, tiroleses etc., seguiram se auto-identificando como tal e em relação à unificação dos Estados nacionais europeus,

' Alfredo Wagner Berno de ALMEIDA, 1989. 
como italianos, alemães, russos - e, também, como brasileiros -, sobrenacionalidades criadas concomitante e simultaneamente aos processos de fixação no Brasil.

A colonização da região Sul atendeu aos interesses das elites intelectuais e políticas de implantar um povoamento com populações tidas como racialmente superiores e provenientes de áreas tidas como mais desenvolvidas. Com o intuito de tornar o País "racialmente mais branco", propiciou condições favoráveis aos imigrantes e com elas, a reprodução das desigualdades instauradas no período escravista, confirmando, assim, as teorias raciais em vigor. A consolidação da nação obteve o suporte ideológico do racialismo, reforçando com ele um projeto de orientação liberal inspirado num tipo de universalismo iluminista que invisibilizou as pautas políticas e sociais dos grupos negros e indígenas. $O$ tipo de ocupação do espaço territorial e a manutenção da fronteira étnica pelos grupos foram, portanto, um relevante fator de reorganização das diferenças, com perdas significativas para os que já se encontravam anteriormente na terra - principalmente os africanos, os indígenas e os chamados "caboclos". ${ }^{3}$

Essa espécie de topografia étnica traduziu-se na continuidade das estratégias de expropriação das terras e na forma como esse projeto se tornou hegemônico e se reproduziu com sucesso até os dias atuais. É também possível depreender as formas de resistência daqueles que foram excluídos do direito de se apropriar bem como de titular suas terras. As linhas demarcatórias dos grupos, para além das diferenças culturais, tornaram-se formas matriciais de continuidade da hierarquização, de novas formas de exploração e, principalmente, da perpetuação das desigualdades sociais.

O lugar ocupado pelos grupos imigrantes europeus, juntamente com os já existentes, reforçou um tipo de fronteira étnica "especular" em relação às teorias raciais importadas da Europa ou recriadas no Brasil, à naturalização das desigualdades, à biologização das diferenças e à legitimação de um modelo nem sempre explícito de segregação. Assim, por exemplo, para se compreender a situação atual dos descendentes de africanos no Sul do Brasil, é crucial o entendimento de como foram percebidos e tratados pelos demais grupos: o contexto intra e intergrupos e a ideologia étnica em cada período da história como uma matriz reveladora, desdobrando-se até os dias atuais, quando as estratégias expropriatórias ainda se reproduzem em larga escala, corroendo as estruturas do Estado, corrompendo os processos administrativos, impedindo que se possa na prática e de fato aplicar as leis democráticas inscritas na Constituição que rege o País.

A forma de ocupação das terras em todo o Brasil se deu por meio da lógica da expulsão dos indígenas e dos negros, da exploração da mão-de-obra compulsória dos africanos e seus descendentes. A territorialidade negra, portanto, foi desde o início engendrada pelas e nas situações de tensão e conflito. Essa constatação reintroduz, na atualidade, um debate sobre questões persistentes e que nos incitam a exercitar um olhar retrospectivo e comparativo, capaz de revelar, nitidamente, os aspectos constitutivos das situações com as quais nos defrontamos no presente. Neste sentido, tornam-se fundamentais os exemplos provenientes das realidades locais para se perceber o que está em jogo nas diversas situações analisadas, suas dimensões, articulações, formas e realces. E é sob esse prisma que a territorialidade negra pode ser referida não a uma realidade equívoca e distante, mas se reportando a uma dimensão simbólica da identidade na qual os negros

\footnotetext{
${ }^{2}$ Alfredo Wagner Berno de ALMEIDA e João Pacheco de OLIVEIRA, 1998.

${ }^{3}$ O processo de construção das fronteiras locais etnicamente territorializadas no Sul do Brasil, movido por uma dinâmica de atração e expulsão dos negros, de instituição e destituição dos grupos, de apropriação e expropriação de terras, foi objeto de discussão em vários projetos de pesquisa iniciados desde 1986 no Núcleo de Estudos sobre Identidade e Relações Interétnicas - Nuer, sediado na Universidade Federal de Santa Catarina.
} 
se organizaram como coletividade nacional, articulações de grande complexidade e que aconteceram desde um processo relacional, multicentrado e altamente dinâmico. ${ }^{4}$

Mesmo em regiões onde não predominou a grande propriedade, como a região Sul, o quilombo como resistência inscreveu-se numa mesma lógica descrita por Alfredo Wagner Berno de Almeida ${ }^{5}$ para o Norte e o Nordeste do País. Esse autor procurou conferir inteligibilidade ao sistema econômico intrínseco às unidades familiares que produziam concomitantemente para o seu próprio consumo e para diferentes circuitos de mercado. No Sul as pequenas propriedades dos negros articularam-se também ao sistema produtivo e a uma lógica de organização social com forte sustentação no parentesco. ${ }^{6}$ As famílias nucleares ou extensas compartilharam e ainda compartilham experiências de vários tipos, trajetórias comuns, situações de discriminação e exploração, circunstâncias de desencontros e desarticulações grupais. Os negros, como integrantes de um segmento desvalorizado e desqualificado, ficaram à mercê da sazonalidade das ofertas de trabalho nos setores em expansão na construção civil, como bóias-frias, safristas ou posseiros, e principalmente na economia informal. Obrigados a mudar de lugar sucessivamente, vão ao mesmo tempo concebendo esses lugares como pontos fixos, compondo e enfatizando essa "cartografia negra" no que tange à própria definição da sua identidade, como grupo local, regional ou nacional, desde uma cidadania que se caracteriza principalmente por ser inferiorizada.

Nas áreas rurais, a desinformação, o esgotamento das terras, o aumento demográfico e principalmente a chegada avassaladora das agroindústrias vão ampliando, ao longo dos anos, os níveis de conflito, o êxodo e a desagregação dos grupos familiares, e, com eles, também os estigmas e as intolerâncias étnicas. A chegada do grande capital em algumas áreas tem tido como conseqüência imediata a reedição de critérios étnicos por meio do discurso do colono empreendedor, capaz de levar adiante essa nova fase do desenvolvimento. Essa chegada do capital transnacional enfatizou de forma ainda mais violenta as diferenças sociais pela segregação espacial e social dos negros nos bairros, nas escolas, nos clubes - para além da tão propalada democracia racial brasileira.

As trajetórias narradas apontam as expropriações de terras e as diversas tentativas de reconstrução de vínculos perdidos como uma condição diaspórica, condição da qual emerge a própria identidade negra como uma identidade singular.

\section{Os movimentos sociais negros $e$ as associações quilombolas}

Os movimentos sociais negros vêm paulatinamente recuperando essas experiências por meio de uma pauta especificamente negra, e, nos anos 30 do século XX, isto se traduziu na Frente Negra Brasileira, a mais importante organização dentre tantas que existiram na luta contra o racismo. No século XXI, as noções se ampliam e o quilombo ressurge como uma forma de denunciar a continuidade da ideologia do embranquecimento e a exclusão dos negros do projeto republicano de modernização do País.

Nos anos de 1970 a 1980, o quilombo é levado à Assembléia Nacional Constituinte, no discurso dos militantes do Movimento Negro Unificado e de parlamentares como Abdias do Nascimento, para transformar-se em dispositivo jurídico capaz de promover a defesa e a efetiva entrada dos descendentes dos africanos na nova ordem jurídica da Nação. Incorporado pela primeira senadora negra, Benedita da Silva, o artigo 68 foi alvo de um

\footnotetext{
4 Situação que foi pioneiramente sistematizada por Fredrik BARTH, 1969.

${ }^{5}$ ALMEIDA; OLIVEIRA, 2005.

${ }^{6}$ Ilka Boaventura LEITE, 2002.
} 
dos muitos projetos que pretendiam regulamentá-lo. Inscrito nas Disposições Constitucionais Transitórias, o artigo 68 enfrentou grandes opositores na Câmara Federal e no Senado e levou quase 20 anos para ser regulamentado. Em seu texto, lê-se: "aos remanescentes das comunidades dos quilombos que estejam ocupando suas terras é reconhecida a propriedade definitiva, devendo o Estado emitir-lhes os títulos respectivos". ${ }^{7}$

Os movimentos negros se rearticularam durante a Assembléia Nacional Constituinte e, após sua promulgação, reforçaram sua retórica sobre a idéia de reparação, da abolição como "um processo inacabado" e da "dívida", em dois planos: a herdada dos antigos senhores e a marca que ficou em forma de estigma, seus efeitos simbólicos geradores de novas situações de exclusão. Abdias do Nascimento, por exemplo, senador da República no período de redemocratização que culminou na Constituinte de 1988, reescreve suas teses sobre o quilombismo, reivindicando uma memória anterior ao tráfico e à escravização dos africanos. Escreve:

O quilombismo busca o presente e o futuro e atua por um mundo melhor para os africanos nas Américas, reconhecendo que esta luta não pode se separar da libertação dos povos indígenas também igualmente vítimas de racismo e da destruição desumana.

O intelectual/parlamentar define o quilombismo como um movimento político dos negros brasileiros, esclarecendo não se tratar de um modelo segregacionista, mas de um movimento que advoga o poder político realmente democrático, implicando a presença da maioria afro-brasileira em todos os níveis de poder.

Desde a abolição do sistema escravista colonial em 1888, o quilombo vem sendo, portanto, associado à luta contra o racismo e às políticas de reconhecimento da população afro-brasileira. Vem recebendo amplo apoio de diversos setores da sociedade brasileira comprometidos com os Direitos Humanos. O dispositivo constitucional inspirou diversos atos e ações de parlamentares de vários partidos políticos; recebeu apoio direto de sindicatos, da Associação Brasileira de Antropologia-ABA; obteve pareceres favoráveis de juristas que integraram a Secretaria de Coordenação da Defesa dos Direitos Individuais e dos Interesses Difusos - SECODID e também da $6^{a}$ Câmara do Ministério Público Federal, conferindo com esses apoios visibilidade e, principalmente, a popularização dos debates sobre as formas possíveis de sua regulamentação em forma de lei.

A expressão "comunidade remanescente de quilombos", no início do processo constituinte, era pouco conhecida. Ela passou a ser veiculada no Brasil principalmente no final da década de 1980 para se referir às áreas territoriais onde passaram a viver os africanos e seus descendentes no período de transição que culminou com a abolição do regime de trabalho escravo, em 1888. Além de descrever um amplo processo de cidadania incompleto, veio também sistematizar um conjunto dos anseios por ações em políticas públicas visando reconhecer e garantir os direitos territoriais dos descendentes dos africanos capturados, aprisionados e escravizados pelo sistema colonial português.

As terras dos quilombos foram consideradas parte do patrimônio cultural desses grupos negros e, como tal, deveriam ser alvo de proteção por parte do Estado.

As reivindicações de organizações de movimentos negros e setores progressistas, como parte da própria reflexão sobre o Centenário da Abolição da Escravidão no País, levadas à Assembléia Constituinte de 1988, favoreceram a aprovação de dispositivos constitucionais concebidos como compensação e/ou reparação à opressão histórica sofrida. A ressemantização do termo "quilombo" pelos próprios movimentos sociais e como

\footnotetext{
7 BRASIL, 1988.

${ }^{8}$ Abdias do NASCIMENTO, 2003, p. 20.
} 
resultado de um longo processo de luta veio traduzir os princípios de liberdade e cidadania negados aos afrodescendentes, correspondendo, a cada um deles, os respectivos dispositivos legais.

1 - Quilombo como direito a terra, como suporte de residência e sustentabilidade há muito almejadas nas diversas unidades de agregação das famílias e dos núcleos populacionais compostos majoritariamente, mas não exclusivamente de afrodescendentes. ${ }^{9}$

2- Quilombo como um conjunto de ações em políticas públicas e ampliação de cidadania, entendidas em suas várias dimensões. ${ }^{10}$

3- Quilombo como um conjunto de ações de proteção às manifestações culturais específicas. ${ }^{11}$

Ao contrário da questão indígena, note-se que não houve anteriormente qualquer jurisprudência que reconhecesse os negros como fazendo parte do País. Um silêncio de um século é então rompido em 1988. A população negra brasileira - sua existência e persistência - foi, naquele momento, reconhecida e reafirmada, em vez de ser subsumida na idéia de embranquecimento do País, tão propalada nas primeiras décadas do século XX pela teoria da mestiçagem, que norteou o pensamento social brasileiro e as políticas públicas ao longo de todo o século.

\section{O quilombo na ordem jurídica e como política de Estado}

A Assembléia Nacional Constituinte de 1988 veio, portanto, restabelecer o Estado de Direito sobre novas bases. Essas novas bases decorreram da incorporação de sujeitos sociais e de direitos. Os negros adquirem com ela uma condição plena de direitos e passam a ser citados e incorporados à concepção de Nação. A Constituição Ihes dá garantia da posse e do usufruto das riquezas do solo, do subsolo e das terras nas quais exercem uma ocupação há sucessivas gerações.

A problemática das terras de quilombos, portanto, foi, a partir de 1988, alvo de atenção e de forte pressão por parte dos movimentos sociais negros, desdobrando-se em várias ações e normas institucionais: administrativas e jurídicas, de âmbito estadual e federal.

Lembra-nos a jurista Elizabeth Rocha que a definição jurídica de quilombos em seus primórdios sempre enfatizou a ocupação coletiva e ilegal da terra. Isto se vê claramente desde o início, quando da resposta do Rei de Portugal à Consulta do Conselho Ultramarino, em 2 de dezembro de 1740, ao conceituar "quilombo" ou "mocambo" como "toda habitação de negros fugidos que passem de cinco, em parte despovoada, ainda que não tenham ranchos levantados nem se achem pilões neles"..$^{12}$ Conforme essa jurista, com o recrudescimento do escravismo, a Lei n. 236, de 20 de agosto de 1847, sancionada pelo Presidente da Província, Joaquim Franco de Sá, diminuiria o número de escravos fugidos sem, contudo, imprimir singularidade ao conceito. Leia-se: "Art. 12- Reputa-se-há escravo aquilombado, logo que esteja no interior das matas, vizinho ou distante de qualquer estabelecimento, em reunião de dois ou mais com casa ou rancho". ${ }^{13}$

Segundo ela, a Legislação republicana que se seguiu não contemplou qualquer redefinição de quilombos, formalmente extintos com a Abolição em 1888. Contudo, restaram elementos paradigmáticos apresentados nas inúmeras pesquisas históricas e antropológicas

\footnotetext{
9 Sobre "remanescentes das comunidades de quilombos" (BRASIL, 1988).

${ }^{10}$ Título I - direitos e garantias fundamentais e Título II, cap. II - dos direitos sociais (BRASIL, 1988).

${ }^{11}$ Artigos 214 e 215 sobre patrimônio cultural brasileiro (BRASIL, 1988).

12 Elizabeth Guimarães Teixeira ROCHA, 2005.

${ }^{13}$ ROCHA, 2005, p. 99.
} 
até então realizadas que irão ser novamente examinados e considerados no momento de elaboração do Decreto n. 4.887/03, que regulamenta o artigo 68 da Constituição Federal. Um dos mais importantes direitos que vêm gerando grandes contestações, principalmente externas, é o da posse comunal e indivisível das terras.

O jurista Dimas Salustiano da Silva, um dos que se especializaram nesse assunto e acompanharam de perto as pesquisas antropológicas realizadas em todo o Brasil, lembranos que por não se enquadrarem tais direitos nas concepções jurídicas clássicas de inspiração liberal: "são direitos de comunidades, de grupos que possuem específicas regras de convivência, em relação às quais as normas de direito privado são estranhas e por isso, impróprias para utilização neste caso". ${ }^{14}$ Suas peculiaridades históricas, segundo ele, não condizem com o tradicionalismo do Direito Civil Pátrio. Apoiada nesse raciocínio, a jurista Elizabeth Rocha nos lembra que:

A expressão esculpida na letra fria da ratio - remanescentes das comunidades dos quilombos - se tivesse sido tomada em sua literalidade, frustraria o sentido infenso à uniformidade interpretativa e estaria a conjurar danos fatais às idéias e aos princípios da Carta Magna, mormente por se saber que o mais trágico legado da escravatura consistiu, precisamente, no asfixiamento da identidade étnica e na fragmentação da consciência coletiva negra diligenciados pelo Estado. ${ }^{15}$

Ainda segundo ela, a desintegração jurídica do estigma da escravidão faz sobrelevar a afirmação do direito étnico no formalismo positivista, realinhando o foco do superado conceito de raça para o plano da identidade. ${ }^{16}$ Portanto, a grande mudança epistêmica é precisamente essa, uma vez que a raça, embora socialmente construída, é inadequada para pensar os grupos humanos no plano de sua diversidade e complexidade cultural.

Conforme conclui a jurista Elizabeth Rocha, é a partir desse avanço que os legisladores concebem o âmbito normativo do artigo 68, transcendendo o próprio texto constitucional e alcançando desde um decreto-lei a dimensão unitária dos valores que regem a Constituição, que concebe o País como pluriétnico e multicultural. É o Decreto n. 4.887 que dá o passo interpretativo importante de desessencializar as práticas socioculturais negras em sua virtualidade política como marca de distintividade. ${ }^{17}$

A jurista Elizabeth Rocha sustenta, em suas reflexões sobre o Decreto n. 4.887/03, que houve um substantivo alargamento crítico que amplia o fim contemplado pela norma, intocável em sua materialidade, e justifica, pelas razões expostas, a titulação coletiva pro indivisa e ad perpetuam sobre aquelas terras como um meio de assegurar a perpetuidade da propriedade às gerações futuras, bem como o patrimônio histórico-cultural brasileiro. A titulação não se reveste, pois, do caráter condominial previsto nos artigos 1.314 e seguintes do Código Civil, nomeadamente, o artigo 1.320 e respectivos parágrafos, que estipulam a licitude da divisão da coisa comum e o prazo máximo de cinco anos para a permanência da indivisão. Como a Lei de Registros Públicos só admite o registro em nome de pessoa física ou jurídica, as comunidades são representadas por suas associações legalmente constituídas, o que não significa deixar de seguir ou praticar as modalidades de usos da terra, os valores e as práticas culturais que vêm praticando, respeitando-se as especificidades de cada uma delas.

\footnotetext{
14 Dimas Salustiano da SILVA apud ROCHA, 2005, p. 99.

${ }^{15}$ ROCHA, 2005, p. 99-100.

16 ROCHA, 2005.

17 ROCHA, 2005.
} 
O Decreto n. 4.887/03, que regulamenta o artigo 68, apresenta outro aspecto inovador se comparado às outras legislações, que é quanto à identificação etno-histórica como critério de identificação do grupo, outorgado pelo artigo $2^{\circ}$, § $1^{\circ}$ do Decreto. A legislação, lembra essa mesma autora com base em observações feitas por Eliane Cantarino O 'Dwyer, incorpora a visão da atual Antropologia, quando esta considera ser a afiliação étnica tanto uma questão de origem comum presumida quanto de orientação das ações coletivas para destinos compartilhados. ${ }^{18}$ Prevalecem por fim, para efeitos declaratórios, os termos da Convenção 169 da OIT sobre povos indígenas e tribais, ratificada pelo Brasil, cujo artigo $1^{\circ}$, alínea "b" 2, preceitua: "A consciência de sua identidade indígena ou tribal deverá ser considerada como critério fundamental para determinar os grupos aos que se aplicam as disposições da presente Convenção". ${ }^{19}$

Outras mudanças originadas dessa nova legislação são decorrentes da própria definição de territorialidade negra ou de "território tradicionalmente ocupado", não guardando correlação com tempo imemorial. Referem-se, deste modo, ao tradicional como forma de uso da terra, segundo os costumes e as tradições de cada grupo ou comunidade.

Decorre daí, a superação civilista do conceito de posse agrária. A extensão teleológica da Carta indica como caminho seguro a percorrer, a interpretação analógica do artigo 231 e respectivos parágrafos, vez que a proteção constitucional às coletividades indígenas e às comunidades remanescentes dos quilombos possui idêntica equivalência valorativa no que concerne à afirmação das prerrogativas territoriais de grupos étnicos minoritários. ${ }^{20}$

No entendimento do Ministério Público Federal, o quilombo decorre e compreende parte dos direitos fundamentais: "Os direitos dos remanescentes de quilombolas ao território é um direito fundamental, que está acima ao de propriedade privada". ${ }^{21}$

Também o procurador de Justiça e da Coordenadoria de Conflitos Agrários de Minas Gerais, Afonso Henrique de Miranda Teixeira, afirmou que: "[...] o direito dos quilombolas à propriedade das terras é atemporal e preexistente. O Estado tem o dever de emitir os títulos para a população quilombola, que deve prevalecer sobre os bens particulares e também os bens públicos". ${ }^{22}$

A ação constitucional de proteção às chamadas comunidades quilombolas tem se ampliado, podendo ser considerada hoje uma prática inovadora no Brasil, embora ainda muito insuficiente. ${ }^{23}$ Volta e meia a grande imprensa e os setores empresariais levantam dúvida sobre os riscos que a regularização dos territórios quilombolas representam para o desenvolvimento, para as fronteiras, para o projeto nacional, entre outros. Isto, no entanto, soa como um contra-senso se comparado aos citados índices de desenvolvimento humano e material dessas áreas - as mais pobres e com maiores índices de desnutrição, saneamento e educação do País.

\footnotetext{
${ }^{18}$ Eliane Cantarino O'DWYER apud ROCHA, 2005.

19 ORGANIZAÇÃO INTERNACIONAL DO TRABALHO, 1989.

${ }^{20}$ ROCHA, 2002, p. 103.

${ }^{21}$ Essa consideração foi feita pela subprocuradora-geral da República, Deborah Macedo Duprat de Britto Pereira, em debate público no dia 30 de novembro de 2007, no seminário Regularização de Territórios Quilombolas em Minas Gerais, organizado pela Comissão de Direitos Humanos da Assembléia Legislativa de Minas Gerais.

${ }^{22}$ Afonso Henrique de Miranda TEIXEIRA, 2007.

${ }^{23}$ Manifesto da Coordenação Nacional de Articulação das Comunidades Negras Rurais Quilombolas " Conaq sobre alterações introduzidas na legislação aplicativa do Decreto n. 4887: "[...] a nova Instrução Normativa fere profundamente os nossos direitos garantidos na convenção 169 da OIT em especial o princípio da boafé centrando fogo no recuo em relação ao conceito de território, auto-identificação, e supressão da competência do INCRA, prevista no decreto 4887/2003, encaminhamos em 01 de setembro de 2008, uma comunicação à OIT manifestando a nossa insatisfação e sugerindo uma série de recomendações [...]" (2008).
} 
As instituições oficiais designadas por meio de Decreto Presidencial para implantar políticas voltadas para os quilombos revelam a abrangência do projeto oficial: quatro agências da Presidência da República, cujos titulares têm status de ministro; secretarias (Seppir/SDH, Casa Civil, Gabinete de Segurança Institucional); seis ministérios (Desenvolvimento Agrário, Saúde, Educação, Cultura, Desenvolvimento Social e Combate à Fome, Advocacia Geral da União); fundações (FCP e Funasa) e também autarquias, como o Incra, responsável direto pelas regularizações fundiárias. Além disso, o Governo Federal estabeleceu uma ampla rede administrativa de execução das políticas públicas nas comunidades quilombolas, além de programas como o chamado Brasil Quilombola.

A implementação dessas políticas, contudo, tem caminhado em descompasso com a titulação dos territórios, ficando as associações quilombolas cada vez mais dependentes do assistencialismo e com menos autonomia para gestionar o desenvolvimento autosustentado de seus territórios.

Segundo o procurador Daniel Sarmento, ${ }^{24} \circ$ Poder Público não tem sido suficientemente ágil na propositura das ações expropriatórias relacionadas ao artigo 68 do Ato das Disposições Constitucionais Transitórias (ADCT) e por razões variadas que vão da escassez de recursos financeiros, passando pelo pagamento das indenizações até a demora excessiva nos procedimentos administrativos tendentes à identificação das comunidades de remanescentes de quilombos e à demarcação dos respectivos territórios étnicos. Os números divulgados sobre os procedimentos técnicos de identificação são muito aquém do esperado e variam conforme a fonte de divulgação. ${ }^{25}$

A vasta legislação disponível hoje se esbarra também com preconceitos e barreiras de todos os tipos. Esbarra-se com tecnologias de dominação instaladas há mais de três séculos e que têm como base de sustentação o controle do acesso à justiça " agora mais recentemente a criminalização dos quilombos ", ${ }^{26}$ tecnologias de controle e manipulação da máquina estatal, da própria legislação, da força repressiva pela apropriação privada de recursos públicos e tantas outras.

O episódio a seguir revela que ainda muito precisa ser feito até que as leis sejam efetivamente cumpridas no Brasil:

Na noite de sexta feira, do dia dezenove de julho de 2008, um grupo de homens encapuzados incendiou três casas da Comunidade Quilombola do Varzeão, localizada no município de Doutor Ulysses (PR), no Vale do Ribeira, divisa com o Estado de São Paulo. $O$ atentado ocorreu por volta das 21 horas. Cerca de vinte pessoas que vivem no local - entre elas cinco crianças - viram-se obrigadas a se refugiar no mato após o início da ação. A titularidade da área é disputada na Justiça pela madeireira Tempo Florestal S/A, por Germene Mallmann e Marjorie Mallmann, que ingressaram com ação de reintegração de posse contra os membros da comunidade quilombola. Justiça concedeu reintegração de posse à madeireira. Integrante da Comunidade do Varzeão, relata que sentiu o cheiro de óleo diesel pouco antes de enxergar as chamas. "Horas

\footnotetext{
${ }^{24}$ Daniel SARMENTO, 2006.

${ }^{25}$ A Comissão Pró-Indio de São Paulo comparou recentemente os dados divulgados pelo Diário Oficial da União de 2004 a 2008 e aqueles do seu próprio programa de monitoramento e concluiu a existência de divergências significativas entre os números de hectares de terras do Relatório Técnico de Identificação e Demarcação " RTID publicado e os que, além do RTID, já possuem as portarias necessárias para o andamento dos processos. Os dados do Incra apontam para o primeiro caso, o número de 53.458.981,93 hectares; os dados levantados pela CPISP apontam 321.432,79 hectares. Já os que teriam tanto RTID quanto portarias publicadas, segundo o Incra, são 188.159,35 hectares, enquanto a CPISP levantou 176.658,37. O grau de disparidade das informações divulgadas desafia os analistas e coloca em dúvida a eficácia do procedimento levado a termo pelo órgão oficial (COMISSÃO PRÓ-ÍNDIO DE SÃO PAULO, 2008).
}

${ }^{26}$ LEITE, 2008a. 
antes, eles já haviam aparecido e feito ameaças. Arrebentaram o nosso portão e tocaram fogo nas casas", através do seu telefone celular, enquanto estava escondido no matagal, à espera da polícia, o depoente relatou à polícia: "Estamos aterrorizados, entramos mais de 600 metros no meio do mato. Temos medo de morrer." Na semana seguinte, o juiz do município concedeu o mandado de reintegração de posse da área. Os integrantes da comunidade acusam a PM de ter disparado tiros de pistola calibre ponto 40 , na última terça-feira (15/7), quando houve a notificação do mandado. "Encontramos três projéteis e três cápsulas deflagradas no local", informa o advogado Pedro Luiz Mariozi, que representa os quilombolas. "Houve abuso de poder por parte dos policiais que, de arma em punho, acompanhados por seguranças particulares, coagiam e intimidavam os trabalhadores rurais." $O$ fato foi em seguida relatado à Secretaria de Estado de Segurança e ao Ministério Públiço do Paraná. Os projéteis e cápsulas foram entregues à assessoria da pasta estadual. ${ }^{27}$

Diante da persistência desse quadro de conflitos que mais parece a reedição macabra das histórias coloniais de capitães-do-mato, o processo político organizativo das associações comunitárias nos quilombos com apoio dos movimentos negros urbanos tem ampliado suas redes, ações e estratégias. Por exemplo, a Conaq tem dialogado diretamente com setores do governo e tem denunciado, inclusive na OIT, OEA e ONU, a inoperância dos setores administrativos do governo; tem também cobrado gestões democráticas e de consulta efetiva aos quilombolas ${ }^{28} \mathrm{~A}$ Conaq lidera a rede de associações comunitárias que está conectada aos países da chamada Pan-Amazônia (Bolívia, Equador, Venezuela, Colômbia e também América Central). ${ }^{29}$

\section{Os impasses e os desafios atuais}

A aplicação dos dispositivos legais em vigor passou a depender da compreensão dos juristas sobre quem são os sujeitos dos direitos referidos no texto constitucional. Os debates suscitados pelo artigo 68 permitiram uma revisão dos velhos estigmas e preconceitos presentes na literatura e nos diversos sistemas classificatórios brasileiros que enfatizavam, até então, a miscigenação como fator predominante na constituição do País, invisibilizando experiências concretas desses grupos em detrimento do imaginário que instruiu os projetos políticos que promoveram a pacificação nacional.

O quilombo como um direito constitucional passou então a abranger um conjunto muito amplo de práticas e experiências, atores e significados - sempre carregando o sentido ou desdobrando-se dele, dos mais diversos modos de reação às formas de dominação instituídas pelo processo colonial escravista -, ampliando-se para um conjunto incalculável de situações dele decorrentes.

Foi, sem dúvida, o prolongamento dessas reações até os contextos pós-coloniais o que conferiu ao quilombo um significado trans-histórico - que o destituiu dos marcos

\footnotetext{
27 DRROSINHA, 2008.

${ }^{28}$ Em já citado manifesto, a Conaq aponta um quadro diferente do que apresenta o governo: "[...] Desde a promulgação da Constituição Federal em 1988, o Cadastro Geral de Remanescentes das Comunidades dos Quilombos - sob responsabilidade da Fundação Cultural Palmares, entidade vinculada ao Ministério da Cultura - registra a existência de apenas 1.228 comunidades quilombolas. Até junho de 2008, apenas 143 comunidades quilombolas haviam recebido o título de propriedade de seu território. Esse número representa apenas $12 \%$ do total de comunidades até agora catalogadas pela Fundação Cultural Palmares e nem 5\% da totalidade estimada pelo movimento social, indicando que a atuação governamental ainda está muito aquém do necessário para garantir o direito à terra previsto nos artigos 13 e 14 da Convenção 169 da OIT [...]" (2008).

${ }^{29}$ Rosa ACEVEDO MARIN e Alfredo Wagner Berno de ALMEIDA, 2006.
} 
cronológicos ou espaciais rígidos -, propiciando a sua correlação ou relação de continuidade com os direitos pleiteados durante o período recente de redemocratização do País. O quilombo assume, portanto, um papel emblemático nas lutas dos negros e em suas reivindicações por cidadania nos diversos períodos da história, sendo este momento atual mais um deles. A sua dinâmica revela que o conjunto de transformações por ele engendrado transcende o que convencionalmente tem sido tratado como agenda política exclusiva do movimento social. As transformações que o quilombo instaura são muito mais amplas e, portanto, de cunho eminentemente identitário.

A pergunta que parece mais recorrente hoje quando buscamos entender esse processo é mesmo sobre a força daquilo que veio a ser caracterizado como "projeto Quilombola", quando o quilombo passa paulatinamente a condensar, a integrar diversas noções de direito que abrangem não só o direito a terra mas todos os demais; quando esse vai do território às manifestações artísticas; quando o direito quilombola quer dizer educação, água, luz, saneamento, saúde, todos os direitos sociais até então negados a essas populações; quando o direito vai do campo à cidade, do individual ao coletivo; e, principalmente, quando o quilombo como direito confronta projetos e modelos de desenvolvimento, questiona certas formas de ser e viver, certos usos dos recursos naturais, seus usufrutos, o parentesco, a herança, as representações políticas e muito mais; quando o quilombo deixa de ser exclusivamente o direito a terra para ser a expressão de uma pauta de mudanças que, para serem instauradas, precisam de um procedimento de desnaturalização dos direitos anteriores: de propriedade, dos saberes supostos sobre a história, dos direitos baseados nas concepções de público e privado, entre tantos outros.

Considero, neste sentido, que o quilombo como direito vem alterando a própria ordem da Nação, dos discursos que sustentam ou sustentaram as mais diversas concepções de Nação, e não é por acaso que há hoje tantas reações que visam desestabilizá-lo: desde o questionamento sobre o suposto sujeito do direito até as formas de exercício do direito assinalado no texto constitucional.

Em recente análise sobre essa questão, busquei discorrer sobre os vários momentos de consolidação do quilombo como um direito. ${ }^{30}$ Procurei demonstrar como o quilombo vai pouco a pouco se instituindo como direito e como isto é fruto de um movimento de longa duração na história brasileira, um movimento persistente e constante de reação às formas de subordinação dos africanos tidos anteriormente como seres inferiores. Esse é um processo profundo e constante que, é claro, não ocorre somente nas fronteiras nacionais, mas em todas as Américas.

Nesse balanço destaquei o ano de 1988 como o marco da mudança pela correlação do Centenário da Abolição da Escravidão com a Assembléia Nacional Constituinte. Esses são os dois grandes acontecimentos políticos - o primeiro de reavaliação e balanço sobre o passado; o segundo de projeção para o futuro -, um retroalimentando o outro, e ambos produzindo uma mudança profunda na situação política dos negros brasileiros.

Mesmo diante da lentidão dos processos de titulação, da erosão das mobilizações atuais provocadas pelas retomadas das velhas estratégias clientelísticas de cooptação das lideranças para os quadros administrativos do Estado e de algumas políticas meramente assistencialistas, o quilombo continua representando insurgência, mais do que acomodação e apaziguamento.

Reafirmo, neste sentido, que o quilombo como direito tornou-se uma espécie de potência que atravessa hoje a sociedade e o Estado - embaralhando as identidades fixas e a configuração do parentesco, do local, regional, nacional e transnacional, e,

${ }^{30}$ LEITE, 2008b. 
principalmente, instaurando grandes dúvidas sobre a capacidade do Estado de ser o gestor da cidadania e o ordenador do espaço territorial.

\section{Referências bibliográficas}

ACEVEDO MARIN, Rosa; ALMEIDA, Alfredo Wagner Berno de. (Orgs.). Populações tradicionais e questões de terra na Pan-Amazônia. Belém: Associação de Universidades Amazônicas, 2006.

ALMEIDA, Alfredo Wagner Berno de. "Terras de preto, terras de santo, terras de índios: uso comum e conflito". In: CASTRO, Edna; HÉBETE, Jean. (Orgs.). Na trilha dos grandes projetos: modernização e conflito na Amazônia. Belém: UFPA/NAEA, 1989. p. 163-196.

ALMEIDA, Alfredo Wagner Berno de; OLIVEIRA, João Pacheco de. "Demarcação e reafirmação étnica: um ensaio sobre a FUNAl". In: OLIVEIRA, João Pacheco de (Org.). Indigenismo e territorialização: poderes, rotinas e saberes coloniais no Brasil. Rio de Janeiro: Contra Capa Livraria, 1998. p. 69-123.

. "Nas bordas da política étnica: os quilombos e as políticas sociais". Boletim Informativo do Nuer: Territórios quilombolas: reconhecimento e titulação das terras, Florianópolis, v. 2, n. 2, p. 15-57, 2005.

BARTH, Fredrik. Ethnic Groups and Boundaries: The Social Organization of Culture Difference. Bergen, Oslo: Universitetsforlaget, 1969.

BOLETIM INFORMATIVO DO NUER. Territórios quilombolas: reconhecimento e titulação das terras. Florianópolis, v. 2, n. 2, 2005.

BRASIL. Constituição Federal. Ato das Disposições Constitucionais Transitórias. Brasília: Senado Federal, Centro Gráfico, 1988.

COORDENAÇÃO NACIONAL DE ARTICULAÇÃO DAS COMUNIDADES NEGRAS RURAIS QUILOMBOLAS. Carta de repúdio aos ataques contra o povo quilombola. Disponível em: www.conaq.org.br. Acesso em: nov. 2008.

COMISSÃO PRÓ-ÍNDIO DE SÃO PAULO. Disponível em: www.cpisp.org.br. Acesso em: 13 out. 2008.

DRROSINHA. Deputado Federal. Disponível em: www.drrosinha.com.br. Acesso em: 19 jul. 2008.

LEITE, Ilka Boaventura. "Os quilombos no Brasil: questões conceituais e normativas". Etnográfica, Lisboa, v. IV, n. 2, p. 333-354, 2000.

. O legado do Testamento: a comunidade da Casca em Perícia. Florianópolis: Nuer/ UFSC, 2002.

. "The Trans-historical, Juridical-formal and Pos-utopian Quilombo". In: GLEDHILL, John. (Org.). Project Rethinking Histories of Resistance in México and Brazil. Manchester: University of. Manchester, 2007. Disponível em: http://jg.socialsciences.manchester.ac.uk/ rethinkinghistories.html. Acesso em: 3 nov. 2008.

. "Humanidades insurgentes: conflitos e criminalização dos quilombos". In: RIFIOTIS, Theophilos; YRA, Tiago H. (Orgs.). Educação em Direitos Humanos. Florianópolis: EDUFSC, 2008a. p. 89-114.

. "Os quilombos e a constituição brasileira". In: OLIVEN, Ruben; RIDENTI, Marcelo; BRANDÃO, Guildo Marçal (Orgs.). A Constituição de 1988 na vida brasileira. São Paulo: Aderaldo \& Rothschild, Anpocs, 2008b. p. 276-295.

LEITE, Ilka Boaventura; FERNANDES, Ricardo Cid. "Fronteiras territoriais e questões teóricas: a antropologia como marco". Boletim Informativo do Nuer: Quilombos no Sul do Brasil: perícias antropológicas, Florianópolis, v. 3, n. 3, p. 7-14, 2006. 
NASCIMENTO, Abdias. O quilombo: vida, problemas e aspiração. São Paulo: editora 34, 2003.

NÚCLEO DE ESTUDOS SOBRE IDENTIDADADE E RELAÇÕES INTERÉTNICAS. Disponível em: www.nuer.ufsc.br. Acesso em: 3 nov. 2008.

O'DWYER, Eliane Cantarino (Org.). Quilombos: identidade étnica e territorialidade. Rio de Janeiro: FGV, 2002.

ORGANIZAÇÃO INTERNACIONAL DO TRABALHO. Convenção $n .169$ sobre Povos Indígenas e Tribais. 1989.

PEREIRA, Deborah Macedo Duprat de Britto. Debate público em 30 de novembro de 2007. In: REGULARIZAÇÃO DE TERRITÓRIOS QUILOMBOLAS EM MINAS GERAIS, 2007, Minas Gerais.

ROCHA, Elizabeth Guimarães Teixeira. "O Decreto 4887 e a regulamentação das terras dos remanescentes das comunidades dos quilombos". Boletim Informativo do Nuer: Territórios quilombolas: reconhecimento e titulação das terras, Florianópolis, v. 2, n. 2, p. 97-102, 2005.

SARMENTO, Daniel. Parecer de 9 de outubro de 2006. Disponível em: www.cpisp.org.br. Acesso em: 3 nov. 2008.

SECRETARIA ESPECIAL DE POLÍTICAS DE PROMOÇÃO DA IGUALDADE RACIAL. Programa Brasil Quilombola. Brasília, Governo Federal, 2005.

SILVA, Dimas Salustiano (Org.). "Apontamentos para compreender a origem e propostas de regulamentação do artigo 68 do Ato das Disposições Constitucionais Transitórias de 1988". Boletim Informativo do Nuer, Florianópolis, v. 1, n. 1, 1996.

TEIXEIRA, Afonso Henrique de Miranda. Debate público em 30 de novembro de 2007. In: REGULARIZAÇÃO DE TERRITÓRIOS QUILOMBOLAS EM MINAS GERAIS, 2007, Minas Gerais.

[Recebido em novembro de 2008 e aceito para publicação em dezembro de 2008]

The Quilombola Political Project: Challenges, Conquests and Present Predicament. Abstract: The quilombola political project has gone through centuries in History in order to consolidate itself as a constitutional right. The quilombo has been increased by means of support of other parts of the Brazilian population, becoming itself part of a national political project aimed at building a democratic society. The contradictions concerning both the legislation and its effective application, however, mean a great challenge nowadays, once the quilombo incorporation within the judicial order has not been sufficient to alter both the practice of expropriation and land control, and along with that practice the precarious situation in which black groups live is evident nowadays. The state action that protects the so called quilombola communities has spread itself and can be considered as innovative practice at present, although it still demonstrates strong inefficiency, requiring a reinforced action as to political participation on part of the black social movements in Brazil.

Keys Words: Quilombo; Ethnicity and Rigths; Identity; Diaspora; Affirmative Action. 